The Sustainable City XIII 319

\title{
DEVELOPING AN ECOLOGICAL ASSESSMENT TOOL FOR SIWAN ECO-LODGES IN THE EGYPTIAN WESTERN DESERT
}

\author{
OLA ALI BAYOUMI ${ }^{1}$, MOHAMED ABDELLAL $^{1}$, MOHAMED FEKRY $^{1}$ \& AMR ALI BAYOUMI ${ }^{2}$ \\ ${ }^{1}$ Department of Architecture, Alexandria University, Egypt \\ ${ }^{2}$ Architectural Engineering \& Environmental Design Department, \\ Arab Academy for Science and Technology \& Maritime Transport, Egypt
}

\begin{abstract}
The aim of this research is to have a better understanding of the real meaning of "eco-lodges" in hot arid regions and from that maintain the local criteria that are generally and unfortunately applied on any building typology of any location. Secondly, we look at achieving sustainable development of the Siwa Oasis through developing a new efficient and green building assessment tool based on credible weightings. The assessment tool is produced from studying the local context features. Moreover, the assessment categories, items and their parameters will be indicated through an ethnographic approach in addition to multi-dimensional (qualitative and quantitative) studies. A questionnaire was applied to 40 participants, $50 \%$ of which are experts and the rest, stockholders, laymen and environmental architecture students (randomly selected and who should have studied at least three environmental courses). Finally, the outcome of the research is a suggested assessment tool for Siwan eco-lodges (Siwan Eco-lodge Rating System (SERS)) that suit the Egyptian Siwan environmental, social and economic perspective.
\end{abstract}

Keywords: eco-lodge, green assessment tool, Siwa Oasis, ethnographic approach.

\section{INTRODUCTION}

Eco-lodges have become a flagship and interesting project of sustainable development during recent years. This type of project guarantees the achievement of economic social and environmental balance, durability and efficiency to the owner, customer or visitor and certainly to the surrounded desert ecosystem. Moreover, rating system is the good way to provide an efficient framework for assessing eco-lodge environmental performance and integrating sustainable development in building and construction processes. According to Mehta (one of the eco-lodge experts and landscape architect), there should be criteria based on environmental, socio-economic feature background for the site of eco-lodge it required to develop [1]. On other hand, Cam and Ong [2] argued that there are roles should be taken in concern of tourism settlement in remote places: first being an institutional setting to raise tourism settlement, environmental awareness; second, setting benchmarks for building environmental practice, to indicate minimum performances standards and safeguards, evaluate eco-lodge design according to previous benchmarks and finally provide a platform for inspiring new designs, technical ideas and solutions [2]. And for that, it was essential to develop an ecological assessment criteria and tool specialized for current and future ecolodges in Siwa Oasis. The research will start with a theme of application design strategy, data collected through qualitative and quantitative approaches and finally the procedure to work on collective data (sampling procedure). The following aim to: (a)_make an assessment model; (b) items; (c) items weighting; and finally (d) categories, indicators and parameters of the assessment tool. At the end, the researcher will develop a green building rating system (Siwan Eco-lodge Rating System (SERS)) based on weighting coefficient system. 
2 CONCEPT OF A GREEN BUILDING ASSESSMENT TOOL IN EGYPT

According to the Housing and Building National Research Center and the Egyptian Green Building Council document of 2011, although the relatively low level of local greenhouse gasses emissions, especially in rural areas as Siwa, Egypt is considered to be one of the countries that at a great risk of global climate change [2].

Moreover, Egypt is one of the developing countries, due to the poor knowledge of well using of the huge availability of renewable and non-renewable natural resources, in addition to the lack trusts of renewable energy usage between Egyptian and Siwan citizens. On the other hand, the Egyptian Ministry of Electricity and Energy claimed that the demand for energy will grow to high levels to reach $3 \%$ annually and $6 \%$ annually for electric consumption and due to economic growth and increasing population, demand of energy is expected to increase $50 \%$ over the next 20 years [4]. Other studies by the Egyptian Ministry of Housing found that $50 \%$ of total carbon-related emissions typically emitted during building life cycle and their usage [2]. This situation forced the Egyptian authority to adopt a number of policies and criteria based on: (a) supporting sustainable development by using clean and environmentally friendly resources; (b) enhancing energy and water efficiency and reliability; (c) sustain operation and maintenance; (d) sustain an efficient indoor environmental quality; and finally (e) reduce waste, embodied energy and $\mathrm{CO}_{2}$ emissions [2].

\section{EGYPTIAN WESTERN DESERT (EWD) AND SIWA OASIS}

\subsection{Egyptian Western Desert (EWD)}

The comparisons in Figs 1 and 2 show that the EWD is developed through the mentioned five oases. The rest of its land is totally dead. Moreover, one of its famous oases, Siwa Oasis, is mainly a low land below sea level, $400 \mathrm{~km}$ away from Matrouh city and totally isolated from other Egyptian cities. Also, the oasis is rich with palm trees, 200 wells in the upper tank "El Hagar Elgiri" and 3,000 mountains inside and surrounding the oasis. Besides, Siwa contains five main high-salted lakes which are Maraqi (700) acres, Aghurmi (960) acres, Siwa $(3,600)$ acres, Zeitun $(5,760)$ acres and finally the Azmuri Lake [3]. Those salty lakes make Siwa one of premium cities for curing and thus one of its kind in medical tourism. On the other hand, the high-salty soil besides the mainly low level land make it difficult to sustain the "Kershef" buildings for long time. This was a good reason for citizens in Siwa Oasis to avoid using previous environmentally friendly material and instead they build houses, tourism settlements and other facilities with lime stone and concrete. Accordingly, the paper is focusing on "eco-lodges" as being one of the key base projects socially, economically and even politically in the Siwa Oasis. Siwan eco-lodges have been built differently since long time ago. Most of them are made of limestone and covered with Kershef to sustain its cultural appearance and environmental qualities [3].

On the other hand maintain its stability and durability against humidity of underground water. Although the success of most Siwan eco-lodges to meet environmental enquires, they do not build according to ecological criteria that respects international or local the question is: is it possible to create an assessment tool for Siwan eco-lodges to follow during long life cycle of the building? And can it be more specific and relative than the Egyptian Green Pyramid rating system (GPRS) [5]? Also the research has four main assumptions:

1. The developed assessment system is directed toward tourism settlements only. Other building types were not on the research scope.

2. Developing the green building rating system for Siwa eco-lodge should be based on analyzing the most utilized practices of developed countries [1], [4]. 


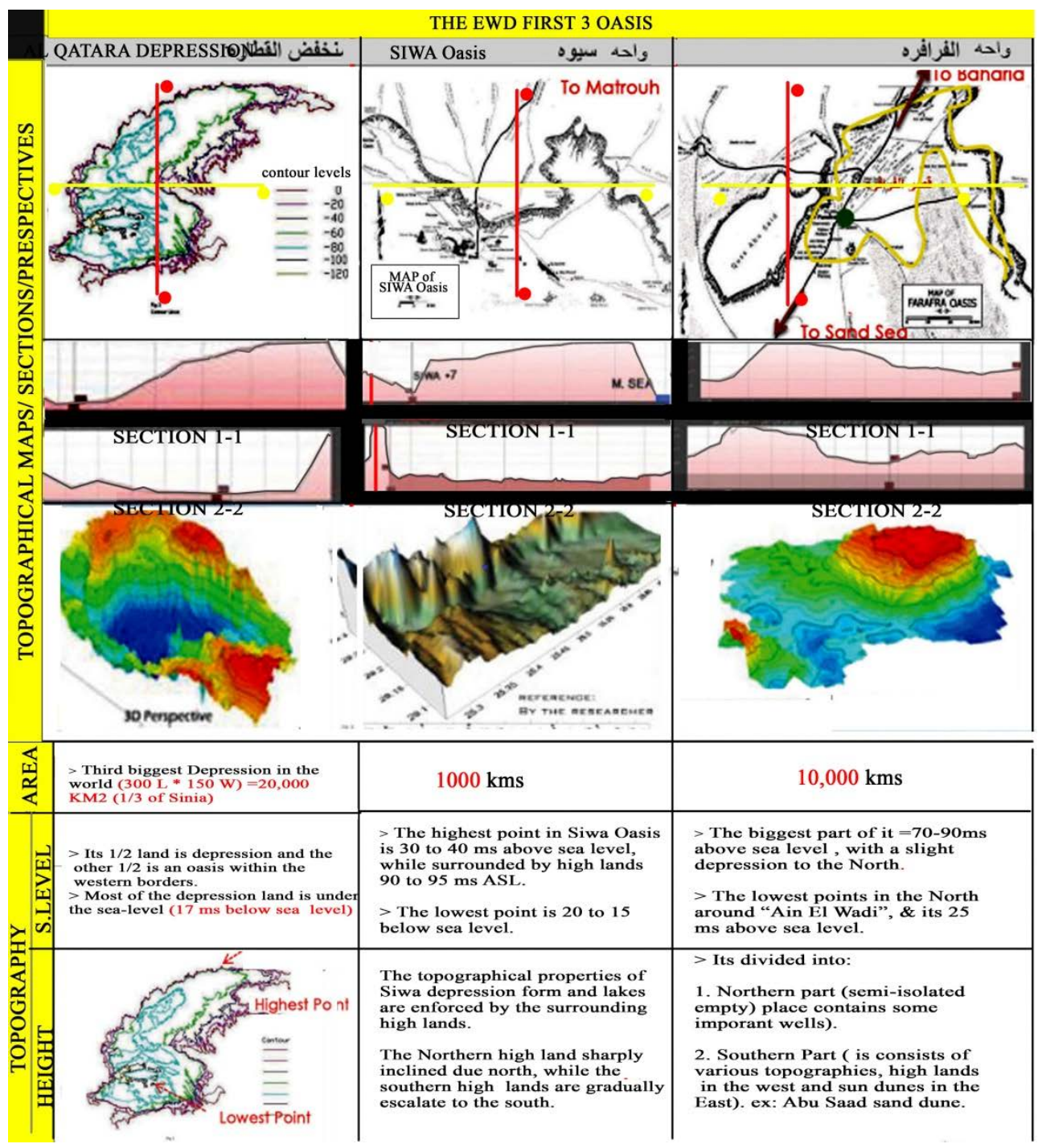

Figure 1: The first three Egyptian Western Desert oasis, including Siwa Oasis. (Source: Authors.)

3. Developed system must include all the life cycle of any eco-lodge: predesign, construction stage and the post-design.

\section{METHODOLOGY}

\subsection{Research design}

At first, to determine the primary variables that will indicate the form of qualitative interview (an interview guide) it was essential to analyze the most comprehensive and developed rating 


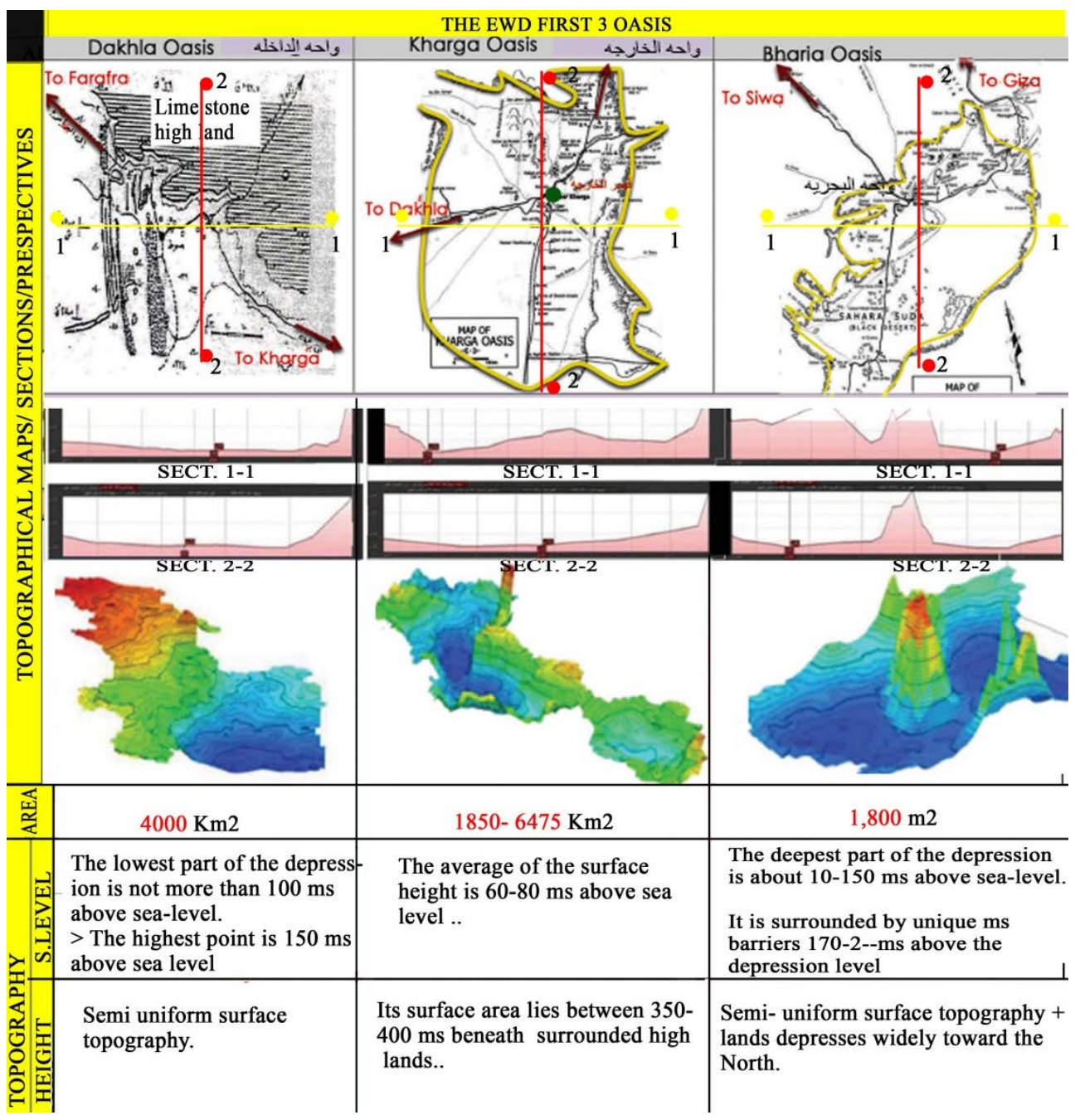

Figure 2: The second three Egyptian Western Desert oasis, excluding Siwa Oasis. (Source: Authors.)

systems to measure sustainability issues. After that the researcher made multiple searches on other rating assessment tools that only serve eco-lodges built or planned to be built in hot arid regions. The result was negative and from here it came the topic of this research. After that, the research mainly depend on structured/formal and unstructured/informal interviews to determine the strength and weaknesses and the element of success of previous systems, in addition to the most suitable of them to be in harmony with Siwan ecological context. The interview was designed as shown in Fig. 5.

The interview was made individually or in groups to examine what people think according to their experience and/or studies. Group interviews were useful as it allows individuals to respond to questions, asking them and exchange comments. 


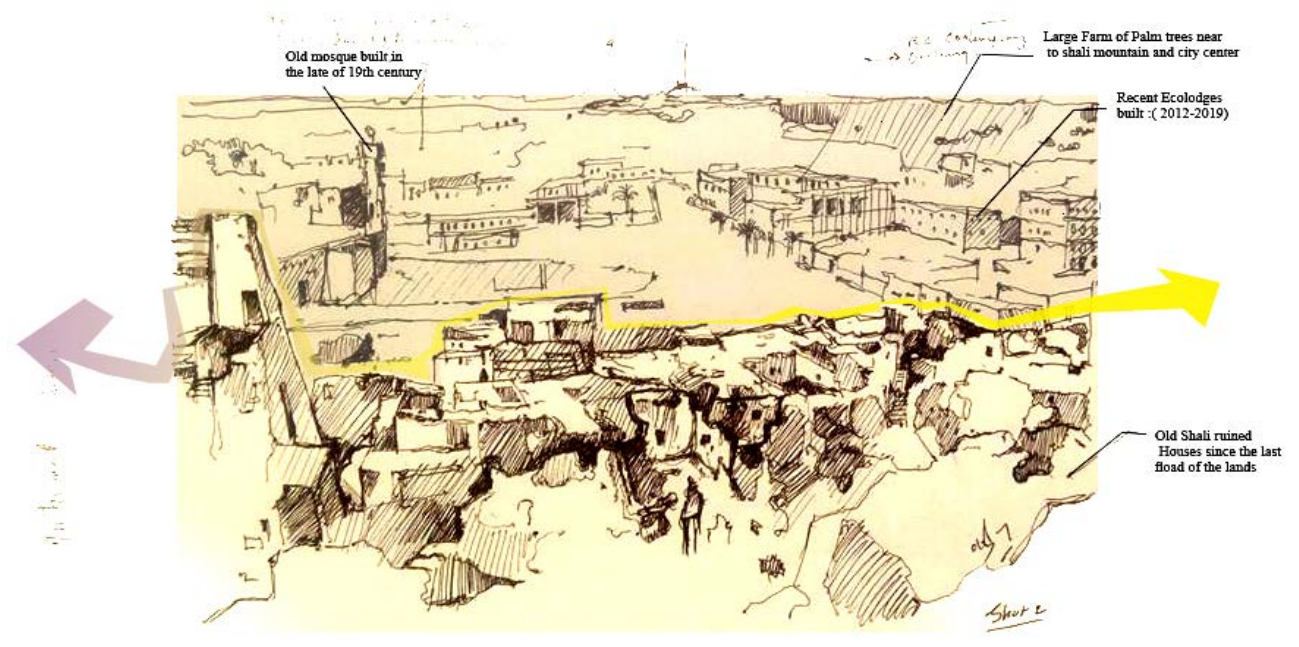

Figure 3: Siwa, old Shali ruins and recently built eco-lodges. (Source: Authors.)

Table 1: Advantages, disadvantages and opportunities of the EWD. (Source: Authors.)

\begin{tabular}{|l|l|l|}
\hline Disadvantages & Opportunities & Advantages \\
\hline $\begin{array}{l}\text { Isolated socially and } \\
\text { economically from other } \\
\text { governmental cities }\end{array}$ & $\begin{array}{l}\text { The possibility to create new } \\
\text { environmental projects as in } \\
\text { (Qattara depression) }\end{array}$ & $\begin{array}{l}\text { Variable and excessive } \\
\text { amount of vegetation } \\
\text { systems (palm and olive } \\
\text { trees, citrus) }\end{array}$ \\
\hline $\begin{array}{l}\text { The lake of investment } \\
\text { projects due to the lake } \\
\text { of people awareness }\end{array}$ & $\begin{array}{l}\text { It is easy to connect Cairo, } \\
\text { Alexandria and other } \\
\text { depressions with each other } \\
\text { to connect social }\end{array}$ & $\begin{array}{l}\text { Large Earth level } \\
\text { difference and spaces } \\
\text { to create new energy } \\
\text { generating projects }\end{array}$ \\
\hline $\begin{array}{l}\text { People refuse to interact } \\
\text { with new social } \\
\text { communities }\end{array}$ & $\begin{array}{l}\text { Local communities There is } \\
\text { lots of opportunities to create } \\
\text { new investments as industry, } \\
\text { tourism and others }\end{array}$ & $\begin{array}{l}\text { Connected with Nile } \\
\text { cities and the Delta } \\
\text { through multiple } \\
\text { prepared roads }\end{array}$ \\
\hline $\begin{array}{l}\text { Digging and transportation } \\
\text { of mineral water need high } \\
\text { supportive cost }\end{array}$ & $\begin{array}{l}\text { Has various types of } \\
\text { metals and mines }\end{array}$ \\
\hline $\begin{array}{l}\text { Outwardly sand dunes } \\
\text { one of the most dangerous } \\
\text { phenomena in the district }\end{array}$ & $\begin{array}{l}\text { The presence of ground } \\
\text { water and the } \\
\text { possibility for Nile } \\
\text { river transition }\end{array}$ \\
\hline
\end{tabular}




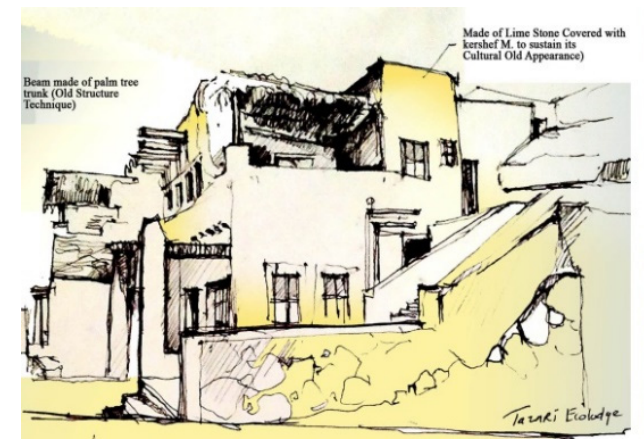

(a)

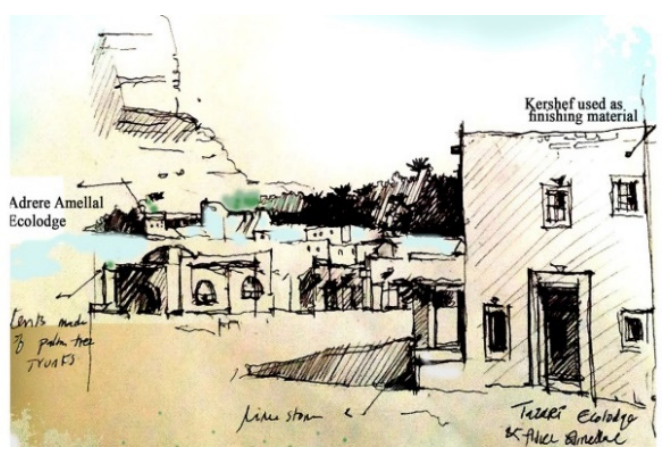

(b)

Figure 4: (a) Tazari eco-lodge; and (b) Siwa relax retreat. (Source: Authors.)

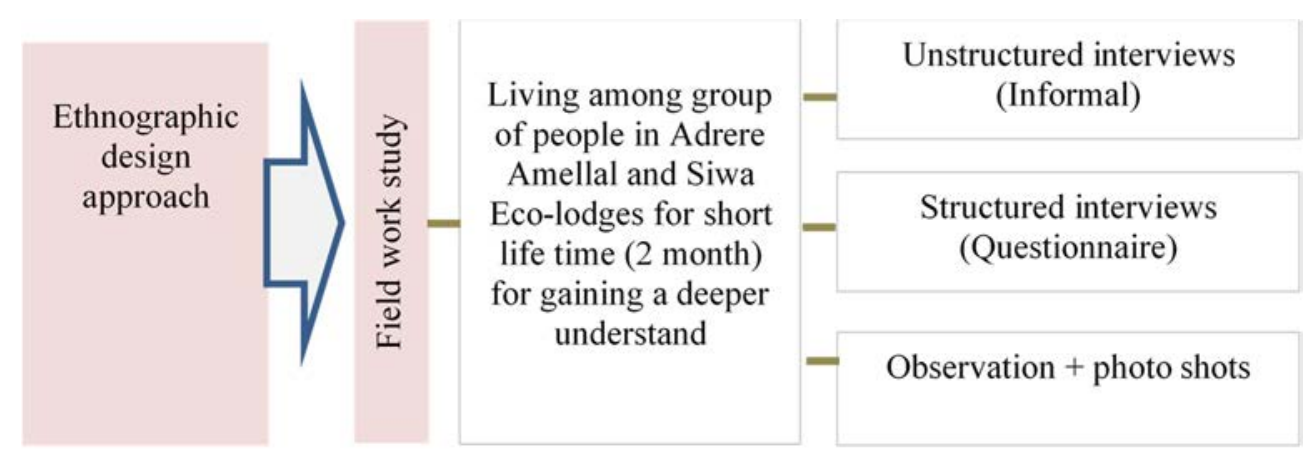

Figure 5: Multi-dimensional research design approach. (Source: Authors.)

The questions were mainly divided in to five main parts:

1. The first part: Should Siwan eco-lodges obtain special criteria different to eco-lodges in other hot arid regions or not)? Please submit your answer with reason(s).

2. The second part: What are the main aspects that should be taken in consideration during constructing a green building assessment tool for "desert eco-lodges"?

3. The third part: Which of those aspects qualities/categories are most important for building an ecological assessment tool for eco-lodges in Siwa Oasis?

4. The fourth part: Organize the aspect's categories that had been chosen in part three according to their importance.

5. The fifth part: Rating each of the following indicators according to their importance. (To build an eco-lodge in the Egyptian Western Desert.)

\subsection{Sampling procedure and the results}

The samples were selected according to the above research design aim. They were participated according to purposive sampling technique. Then, the participants were mainly divided in to two groups. The first $(\mathrm{n}=20(50 \%))$ were experts in the academic field, building field and/or designers and engineers that had studied and lived in Siwa Oasis. This group had structured interview (Questionnaire) and the mean of their answers were presented as in Fig. 
6. On other hand, the second group were composed of laymen (general public people such as builders, journalists and other governmental agents that had previous practice of the research field), environmental, architectural and engineer students. The students should at least have finished two environmental courses.

Mean of assessment aspects:

a. Env.; b. Social; c. Economic

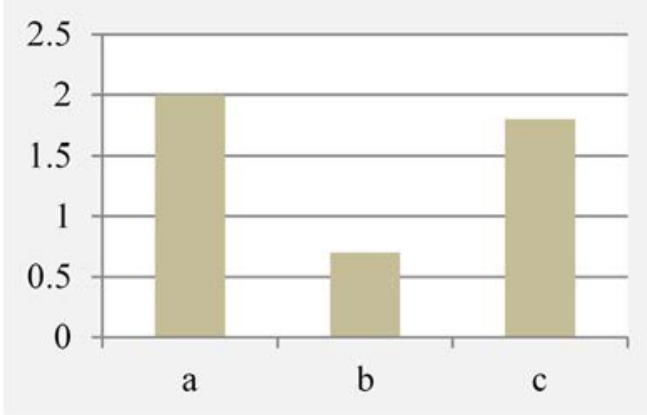

Main categories of environmental aspects: a. Site; b. Energy eff.; c. Water eff.;

d. Material; e. IEQ; f. Waste; g. Cost and economic category.

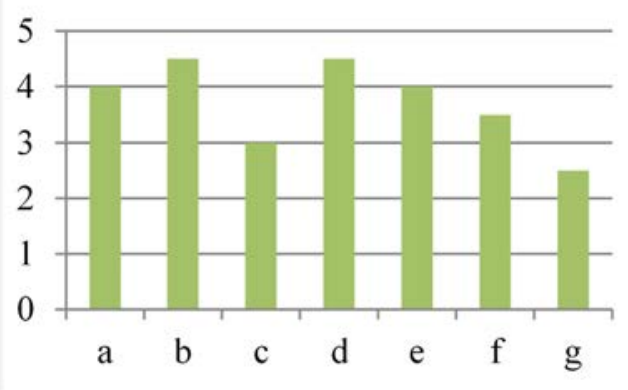

Figure 6: Ranking the mean of assessment aspects and the main categories of environmental aspect as it is considered the most important aspect according to formal and informal interviews. (Source: Authors.)

\subsection{Developing the assessment model of the (SERS)}

\subsubsection{Assessment items}

In order to establish the previous context Siwan environmental items (site (S), energy efficiency (EE), water efficiency (WE), material (M), indoor environmental quality (IEQ), waste and pollution (W\&P) and cost and economics (C\&E)), it was essential to do this cyclic procedure (Fig. 8).

\subsubsection{Assessment item weighting}

Due to the multi-dimensional study strategies of the research that respects various environmental, social and economic issues, it was essential to build a comprehensive and flexible weighting system for indicators/items. AHP method solves the purpose of the study and helped in indicating the weighting of each assessment item (Table 2).

4.3.2.1 Analytical hierarchy process (AHP) method. After the completion of the second procedure (the questionnaire), it was essential to generate the AHP system. This mathematical method/system was developed by Thomas Saaty in 1980 in order to: (1) solve complex decision making to a series of one-on-one comparisons; (2) depending on identifying and weighting selected criteria (in the first step); (3) take in consideration to both qualitative and quantitative aspects; and (4) reduce pitfalls of team coordinated and minimize bias in the decision making. 
Site Indicators

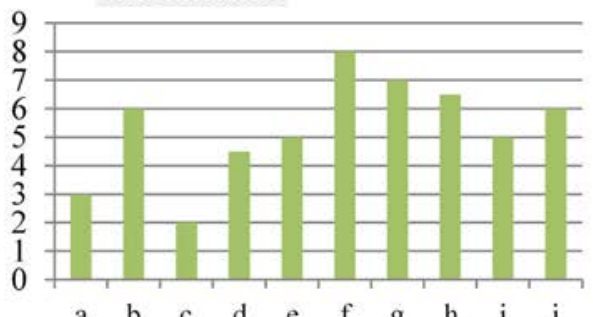

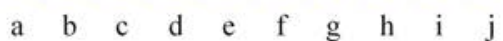

m Site Indicators: a. Microclimate b. Landuse c. Landform. d. Infrastructure Efficience .e. Site Energy Resources f. Building surroundings. g. Landscape Design. h. Housing Design. i. Techniques of Site Construction. j. Transportation.
Energy E. Indicators

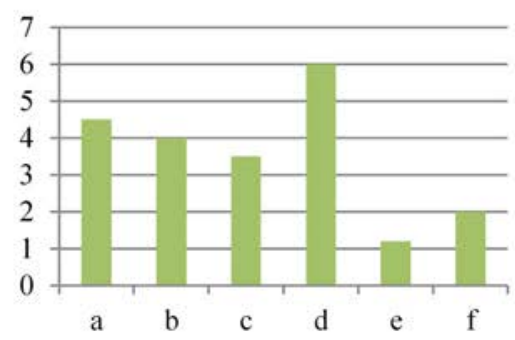

= Energy Efficiency Indicators: a.Renewable Energies b. Heating/ Cooling System c. Natural lighting d. Performance of Building envelope e. Mechanical Systems. f. Green gase emission.
IEQ Indicators

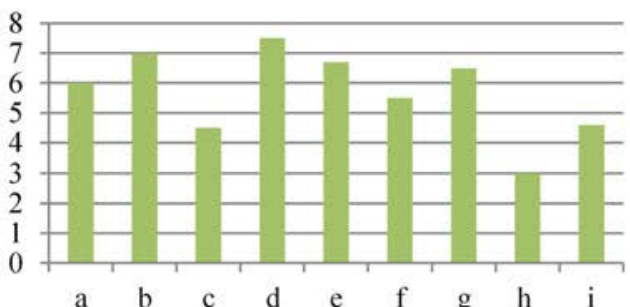

$=$ IEQ: a. IAQ b. life quality c.Day light d. Thermal comfort e. Visual quality f. Occupant quality g. Ventilation quality h. Safety i. Acoustic control.
Economic Indicators

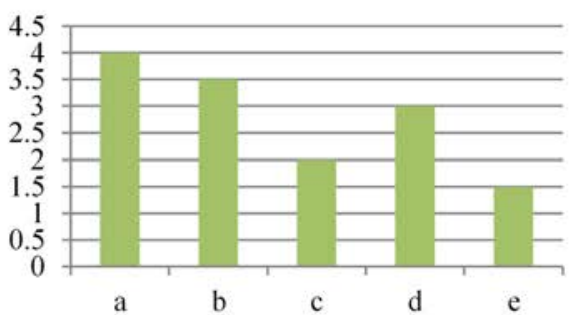

m Economic Indicators: $a$. Energy Efficiency b.

Site c.Construction material d. water

Efficiency e. Waste managment

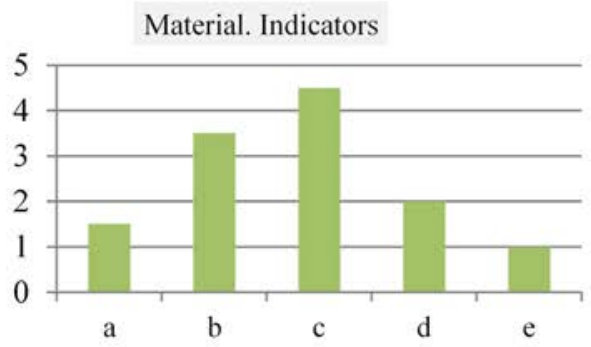

= Material Indicators : a. Recycling Material b. Materials Environmental Impact c. Local Materials d. Reusage of Resources of Material e. Rennovative Concrete material

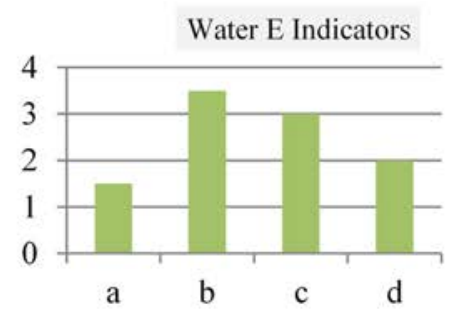

w Water Efficiency : a. Landscape Water Efficiency b. Water Conservation c. New Reduction water Technologies d. Water Use

Figure 7: Ranking the mean of indicators considered in Siwa Oasis according to formal and informal interviews. (Source: Authors.) 


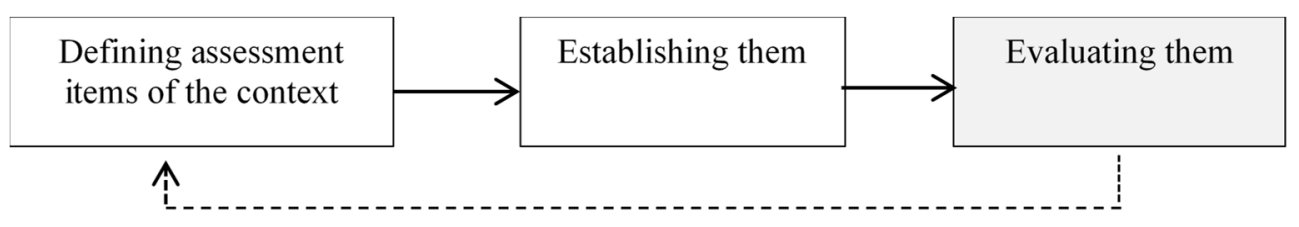

Figure 8: Establishing assessment item cyclic process. (Source: Authors.)

Table 2: Decision matrix (pair-wise decision) by the researcher with respect with respondents views using BPMSG AHP software. (Source: Authors).

\begin{tabular}{|l|c|c|c|c|c|c|c|}
\hline & $\mathrm{S}$ & $\mathrm{EE}$ & $\mathrm{WE}$ & $\mathrm{M}$ & IEQ & W\&P & C\&E \\
\hline Site & & 0.33 & 4.00 & 0.0 & 1.00 & 2.00 & 6.00 \\
\hline Energy efficiency & 3.00 & & 5.00 & 1.00 & 3.00 & 4.00 & 7.00 \\
\hline Water efficiency & 0.25 & 0.20 & & 0.17 & 0.25 & 2.00 & 5.00 \\
\hline Material & 2.00 & 1.00 & 6.00 & & 3.00 & 4.00 & 6.00 \\
\hline Indoor environmental quality & 1.00 & 0.33 & 4.00 & 0.33 & & 3.00 & 5.00 \\
\hline Waste and pollution & 0.50 & 0.25 & 0.50 & 0.25 & 0.33 & & 6.00 \\
\hline Cost and economics & 0.17 & 0.14 & 0.20 & 0.17 & 0.20 & 0.17 & \\
\hline
\end{tabular}

Principle Eigenvector solution: 6 iterations, delta $=4.8 \mathrm{E}-8$.

Eigen value $=7.553$.

\subsubsection{Coefficient system for weighting}

After developing the assessment indicators, it was essential to establish weighting system for them to be used as reference within which the tool is developed. AHP method was used for transforming human qualitative judgments into quantitative analysis based on principles of decomposition and synthesis priorities. The complex judgments is decompensated according to its main components to set criteria for evaluation and find decision alternatives. Moreover, through pair-wise comparison and BPMSG AHP software the researcher had derived the criteria weights and priorities of investment alternatives (Fig. 9 and Table 3). All main relative and primitive weight (relative importance) of each categories/elements of the system's context was derived according to Saaty's scale (1-9 scale). The relative importance is measured as follows: $1=$ equal importance, $3=$ weak importance, $5=$ strong importance, $7=$ demonstrated importance, $9=$ absolute importance, 2 and $4=$ intermediate values, 6 and $8=$ adjacent judgments.

By using BPMSG software to achieve AHP method, the weights of assessment items were measured. Energy Efficiency and Material are calculated and are found that they are the most important assessment category values. They represent $28.8 \%$ and $27.5 \%$ respectively of the total certification which are more than half of the total weightings of the criteria. The rest of the categories are defined in Table 3 and their priorities are shown in Fig. 9.

4.3.3.1 Assessment method to measure the credibility of any ecological tourism settlement in Siwa Oasis (according to previous coefficient weightings). In order to find the final result of the assessment, first, each parameter of the project (which has been scored its greenness value by three ordinal scales $1,0.5$ or 0 ) should be multiplied by their parameter weighting coefficient. 


\section{Priority}

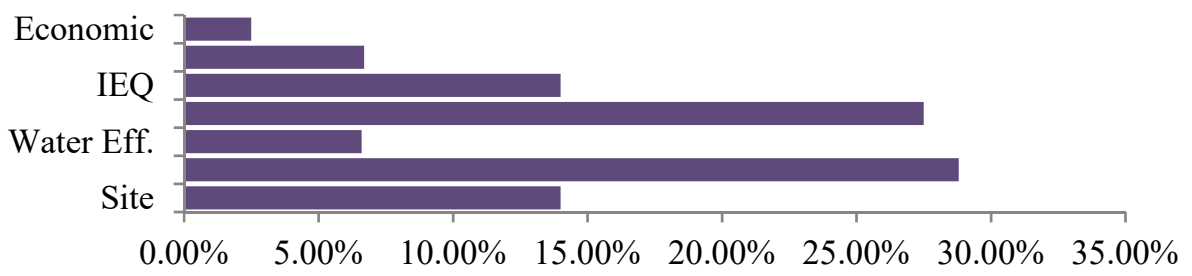

Figure 9: Priorities of assessment categories - weighting of assessment items. Number of comparisons $=21$; consistency ratio $(\mathrm{CR})=6.9 \%$. (Source: Authors.)

Table 3: Assessment category weighting results.(Source: Authors.)

\begin{tabular}{|c|l|c|}
\hline Items & Assessment categories & Their weights \\
\hline $\mathrm{S}$ & Site & 0.14 \\
\hline $\mathrm{E}$ & Energy efficiency & 0.288 \\
\hline $\mathrm{W}$ & Water efficiency & 0.066 \\
\hline $\mathrm{M}$ & Material & 0.275 \\
\hline $\mathrm{IEQ}$ & Indoor environmental quality & 0.14 \\
\hline $\mathrm{W} \& \mathrm{P}$ & Waste and pollution & 0.067 \\
\hline $\mathrm{E} \& \mathrm{C}$ & Economic and cost & 0.025 \\
\hline
\end{tabular}

Second, the result of the parameter will be added (appear) in their indicators. The total result of the indicator will be multiplied by their indicator weighting coefficient.

Third, the result of the indicators will be added (appear) in their categories. The total score of the categories will be multiplied by their coefficient. Finally the main result will present the contribution of all categories and the submission of all weights. Those results have been presented graphically as shown in Fig. 11.

- Score of measured parameter $(1$ or 0.5 or 0$) *$ Parameter weighting coefficient $=$ Parameter result (of next indicator)

- Total result of previous indicator's parameters * Indicator weighting Coefficient $=$ Indicator Result (of next category)

- Total result of previous category's indicator * Category weighting coefficient $=$ Category result (CR)

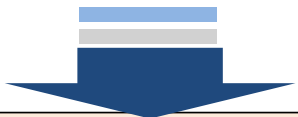

Final result of assessment tool $=\mathrm{CR}($ site $)+\mathrm{CR}$ (Energy) $+\mathrm{CR}$ (Water) $+\mathrm{CR}$ (Material) $+\mathrm{CR}(\mathrm{IEQ})+\mathrm{CR}$ (Waste) +CR (Economic)

Figure 10: Assessment equation to measure the credibility of any eco-lodge in the Siwa Oasis. (Source: Authors.) 


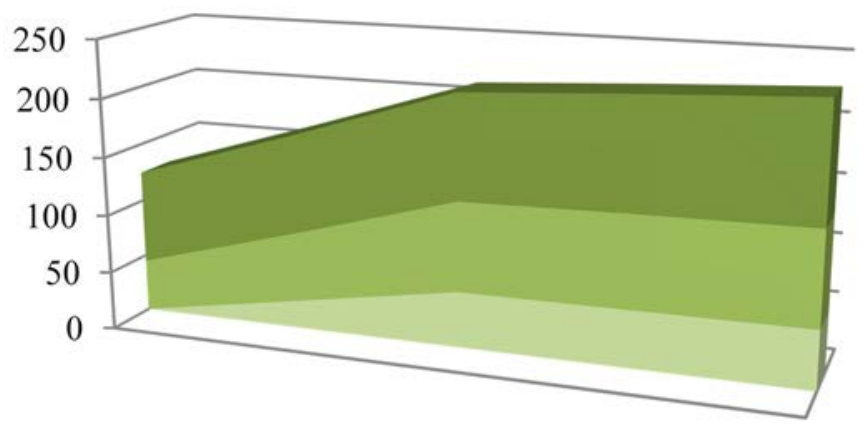

- High Greenness

- Intermediate Greenness

Low Greenness

Figure 11: Certification criteria green standards, used as a reference to measure score categories of eco-lodge projects depending on resulted coefficient weightings. (Source: Authors.)

\section{CONCLUSION AND RECOMMENDATIONS}

The SERS is a tool for architects, engineers and contractors for building any eco-lodge in the Siwa Oasis. This tool is limited to ecological tourism settlements only, in contrast to other international rating systems that serves different types of buildings with same weightings and some of them include other majors as landscape and urban qualifications. The coefficient weights found for each assessment category of the tool integrated in an international greenness standards helped to provide a more holistic assessment approach depending on careful study of Siwan local context and building technologies.

The assessment SERS tool is depending on the categories (the outer boundaries), indicators (the middle of the system) and finally their parameters (the core of the system). All of the previous assessment items were addressed by three main methods (informal interviews, formal interviews (questionnaire), observational sketches and shots).

This methodology gave realistic results to the local circumstances of the place, people and the ecological differences in Siwa Oasis

Finally this research suggests number of recommendations:

a. Developing this system is an essential need to develop one type of project, thus, deep knowledge, scientific research and physical experience are required to achieve the above goal.

b. The assessment tool should be built according to fully understanding of the local context, accompanied by the experience of Experts, designers and other agencies.

c. Researchers should take advances of other international and regional rating systems during developing the systems of their countries. This will help to reduce errors and enhance their inputs.

\section{REFERENCES}

[1] Mehta, H., Best Practices in Eco-lodge Planning Design and Guidelines, Vol. 1, Red Sea Sustainable Tourism Initiative, Cairo, 2005.

[2] Cam, B.L. \& Ong, C.N., Building environmental assessment tools and multidimensional pathways towards sustainable architecture. SB05Tokyo, The 2005 World Sustainable Building Conference, pp. 1738-1745, 2005.

[3] El-Demirdash, M.A., The Green Pyramid Rating System. Housing and Building National Research Center: Giza, 2011. 
330 The Sustainable City XIII

[4] Vivan, C., The Western Desert of Egypt, The American University in Cairo Press: Cairo, 2002.

[5] Ministry of Housing Utilities and Urban Development, Urban planning strategy of Siwa Oasis, Matrouh Government, Report 3, Volume 1, 2013. 